UCL ENVIRONMENTAL CHANGE

RESEARCH CENTRE
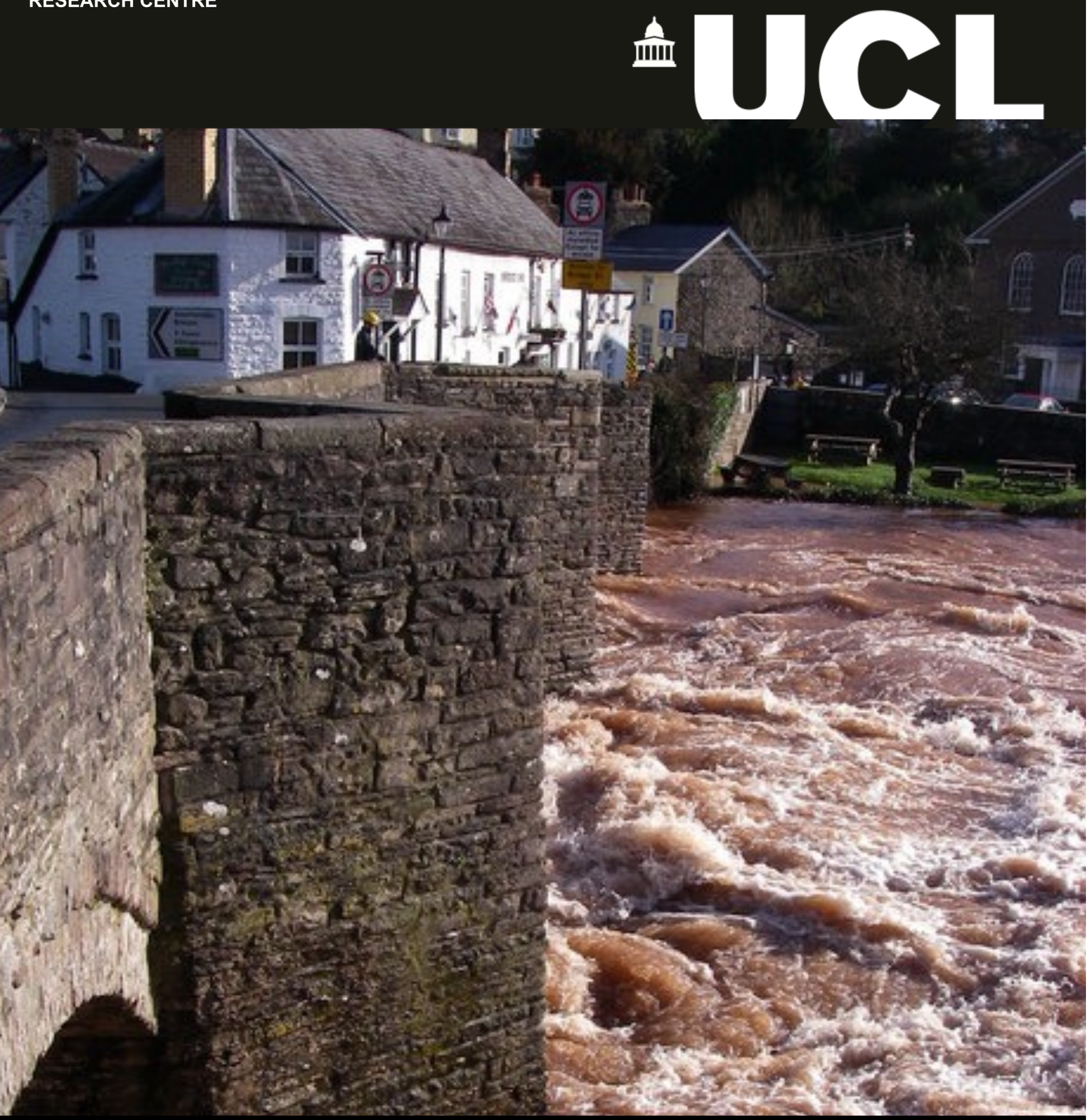

Extreme UK Rainfall and Natural Climate Variability: Combining models and data

ECRC Research Report Number 175

C. Brierley, M. Simpson, I. Roy \& C. Nankervis 


\title{
Extreme UK Rainfall and Natural Climate Variability: Combining models and data
}

\author{
Chris Brierley (UCL Geography) \\ Mike Simpson (Oxford ECI)
}

Indrani Roy (UCL Geography, University of Exeter)

Chris Nankervis (Weather Logistics)

ECRC Research Report Number 175

\author{
Environmental Change Research Centre \\ University College London \\ Pearson Building, Gower St. \\ London, WC1E 6BT
}

Cover photo: Crickhowell Bridge in the Usk/Wysg catchment.

Copyright Alan Bowring. 


\section{Contents}

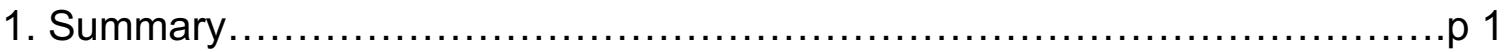

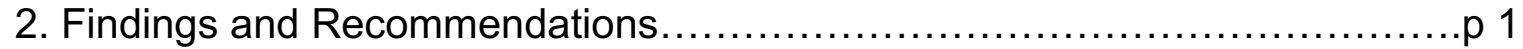

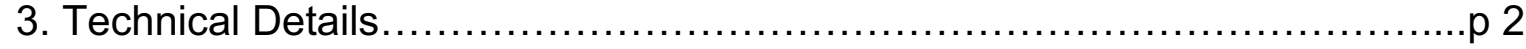

3.1 Observational data

3.2 Extreme metrics

3.3 Natural variability

3.4 Climate models

3.5 Damage function

3.6 Spatial Heterogeneity

3.7 Anthropogenic climate change

4. Figures and Table. .p 5

Figure 1: Rainfall return levels and the North Atlantic Oscillation

Figure 2: Damage return levels and time period

Figure 3: Projections of cumulative UK rainfall on very wet days

Figure 4: Local variations in cumulative rainfall percentage

Table : UK damages and damage function behaviour.

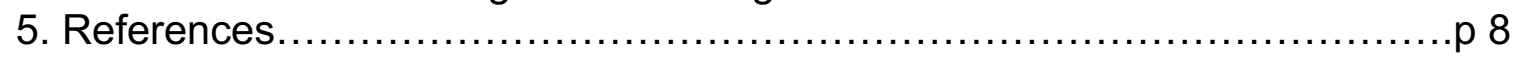




\section{Summary}

The return periods for extreme events are estimated from observational datasets. Often those datasets are relatively short in comparison to timescales of natural climate variability; potentially introducing a systematic bias into the extreme estimates. Here we combine observations with global climate models to show that this bias is statistically insignificant for the case of extreme UK-wide rainfall estimates. This is unlikely to hold for other locations and spatial scales, yet the methodology we have developed provides a simple approach to quantify the bias for other cases.

\section{Findings \& Recommendations}

The most worrying features of climate change arise from its impacts on extreme events, such as floods, droughts and windstorms. This is true for natural changes in climate (termed natural climate variability) as well as for those caused by human activities. A lot of effort is currently going into understanding the consequences of anthropogenic climate change - both on catastrophe modelling and from a systemic economic perspective. The role of natural climate variability on extreme weather is well established. For example, an El Niño leads to decreased hurricane activity along the Gulf Coast. Estimating the recurrence of an extreme event involves sophisticated statistical extrapolation beyond a relatively short sequence of observations. But what happens when these observations do not sample the range natural climate variability - by missing any EI Niños for example?

Here we provide an illustration of the scale of this issue. We look at heavy rainfall across the U.K. as the Met. Office has collated some of the longest high-quality daily rainfall records. We also make use of over twenty state-of-the-art climate models to provide synthetic observations. The precise metric we use is the sum of rain falling each year on the $5 \%$ of wettest days. Most of these days occur in winter. Similar to industry practice, we presume a stationary climate for this analysis. This is akin to saying that the impacts of human-caused climate change are negligible over the historical period under investigation.

Most of the damaging rain-related events in the U.K. are caused by winter storms. The storminess over the whole of Western Europe is related to a climate pattern called the North Atlantic Oscillation (NAO). This varies year by year, but also will favour one phase or the other for a decade or two. The Atlantic Multidecadal Oscillation (AMO) involves shifts in sea surface temperature on 30-40 year timescales, and its warmer temperatures deliver more moisture to the U.K. A typical length of weather observations of a quarter of a century might only catch one phase of these oscillations.

We can interrogate climate model to find out how the return estimate of an extremely wet year relates to these two climate modes. There are over twenty different climate models that have provided historical simulations with the necessary daily outputs spanning 18502005. Each simulation calculates its time series of natural climate variability. These simulations have been subdivided into shorter samples and the 200-year return level estimated from each sample. The resulting model-derived estimates can be compared to the return level from observations (Figure 1). It is clear that the 5-95\% range from observations only encompasses roughly half of model-derived estimates. This may indicate that the volatility (uncertainty) calculated from observation is underestimated. 
The indices categorising the NAO and AMO are also recorded. This results in sufficient synthetic data to calculate the correlations between return levels and phase of the climate mode. Little evidence of a statistically significant relationship is found. The fact there is not a statistically significant relationship does not preclude a subtle dependency of estimate return levels on climate variability. For example in Figure 1, the simulated return levels are coloured by whether the NAO is negative (blue), neutral (black) or positive (red).

A somewhat similar analysis can be performed to track climate changes with time (Figure 2). Again no statistically significant relationship is seen in total, yet an obvious trend is visible. In this instance, we have also applied a damage function to convert the rainfall totals into expected economic losses. One fundamental difference between the two factors is that we anticipate the increasing magnitude of climate change to cause an increasing systematic bias in estimates of return level. Any uncertainties from climate variability should be remain of a similar size throughout. Since a large synthetic dataset has been created, it could be used to model and correct for the climate variability and change. For the UK precipitation shown here, a correcting for the observed phase of the natural variability would result in a downward shift of $7 \%$ of the $200-\mathrm{yr}$ damage level. This regressive model also suggests the warming seen in the UK in 2015 increases the 200-yr return level by $£ 50 \mathrm{~m}$.

This report only presents an analysis of extreme precipitation over England and Wales. We have shown that climate variability does not impact estimates of return levels over the country, despite influencing year-to-year rainfall values. This occurs because precipitation itself involves high levels of stochastic, weather noise combined with the fact that 20 years is sufficient to average over multiple periods of the North Atlantic Oscillation. It is doubtful this situation will always be the case. The availability of model simulations would allow a similar analysis to be performed for temperature and precipitation extremes anywhere around the globe. The existence of the simulations categorising the relationship also allows a scaling factor to be identified to correct observed records where this does occur.

\section{Technical Details}

\subsection{Data Sources}

The longest quality-controlled record of daily rainfall goes back to 1931. It represents the average precipitation over England and Wales and is known as by the acronym, HadUKP (Alexander \& Jones, 2000). It is available via free download from the Hadobs website (Met. Office, 2016)

\subsection{Extreme Metrics}

The results shown in this reports use a metric cryptically known as R95pTOT. This translates to the total amount of rainfall on very wet days during each year. It is created from a daily precipitation time series and uses a self-referential way of identifying 'very wet' days. This involves creating a climatology and calculating the 95th percentile of rain rate.

The R95pTOT was identified by the Expert Team on Climate Change Detection and Indices (ETCCDI, 2009). Here it has been calculated using the climdex.pcic set of R libraries (Bronaugh et al., 2015). This metric is chosen as it seems to the most relevant for the insurance industry, as well as for pragmatic reasons. It accumulates over roughly 10 days each year. Several other extreme rainfall metrics were also investigated. 
To correct for biases in the climate model simulations, we perform the analysis using the proportional metric (i.e. the fraction of the climatological total annual rainfall falling on very wet days). All results are converted back into absolute rainfall amounts by multiplying by the observed cumulative annual precipitation $(884.3 \mathrm{~mm} / \mathrm{year}$ ) during the climatology period (1971-2000).

\subsection{Natural Variability}

The North Atlantic Oscillation (NAO) is a large scale see-saw in atmospheric mass between the polar low and the subtropical high in the north Atlantic region; it is the dominant mode of climate variability during winter around the North Atlantic. A positive phase of the NAO shows a stronger North-South pressure difference in the Atlantic. It is related to stronger and frequent winter storms travelling on a more northerly track and is associated with wet and warm winters in Northern Europe. Here we measure it the normalised sea level pressure difference between $\left[20-50^{\circ} \mathrm{N}, 90^{\circ} \mathrm{W}-60^{\circ} \mathrm{E}\right]$ and $\left[55-90^{\circ} \mathrm{N}\right.$, $\left.90^{\circ} \mathrm{W}-60^{\circ} \mathrm{E}\right]$ (Stephenson et al., 2006).

The Atlantic Multidecadal Oscillation (AMO) measures how much warmer sea surface temperature averaged over the North Atlantic is than the global value. The time scale of the AMO is 20-40 years. Here we use the Trenberth \& Shea (2006) definition of AMO as being the difference between sea surface temperature averaged between $0-60^{\circ} \mathrm{N}, 0-80^{\circ} \mathrm{W}$ and averaged between $60^{\circ} \mathrm{S}-60^{\circ} \mathrm{N}, 0-360^{\circ} \mathrm{E}$.

\subsection{Climate Models}

Climate models (formally termed 'coupled general circulation models') are some of the most sophisticated algorithms available. They solve the fundamental equations of motion for the atmosphere, ocean, sea-ice and land surface at tens of thousands of locations simultaneously. The atmospheric components are derived from weather forecasting models.

A co-ordinated set of experiments were performed by all modelling centres across the globe in support of the Intergovernmental Panel on Climate Change's (IPCC) most recent assessment report (Flato et al., 2013). As the Earth's atmosphere can only be observed once over the 20th Century, historical simulations from these climate models are treated here as alternate realisations of past climate variability.

The results of all the IPCC simulations are freely available via the Earth System Grid Federation. Only a subset of the simulations have posted daily output data. The Canadian Center for Climate Modelling and Analysis has computed and released annual extreme indices from this data for the community (Sillmann et al., 2013). We have accessed the data for the United Kingdom (Figure 3) via the IPCC's Climate Change Atlas (van Oldenborgh et al., 2013).

\subsection{Damage Functions}

Damage curves or damage functions relate the severity of a natural hazard to the probable consequential impact, typically in financial terms (Oppenheimer et al. 2014) or some cases as human costs (Penning-Rowsell et al. 2005). They are difficult to estimate, and the outcomes of hazard studies may be highly sensitive to their correct identification (Smith 1994). Factors such as flood warnings and defences also reduce incurred losses.

Nevertheless, simple damage functions are widely implemented and popular due to their transparency (Ackerman \& Munitz 2012). 
Plots of damage as response variables to flood depth are known as depth-damage curves. Depth-damage curves can be used in combination with depth-frequency plots to determine the typical costs associate with events of a given return period. An alternative is to infer the damage-frequency relationship directly. Figures for the likely damage to the UK of average annual flooding along with 1-in-100 and 1-in-200 year flood events were acquired from the Association of British Insurers (Dailey et al. 2009) and combined with the total rainfall falling on very wet (>95\%) days over the year from the HadUKP dataset (section 3.1). As zero damage may occur at low flood levels (Green 2003), the damage-frequency curve is evaluated on the interval between the mean annual maximal flow/annual damage and the 1 -in-200 event. The function derived from this approach is damage $(£ \mathrm{~m})=0.0006$ R95pTOT^2.7676 (mm).

The 10 largest cumulative daily rainfall values were identified along with their associated damage and insurance claims (Table). This illustrates the high uncertainty associated with the calculation of damage from precipitation frequency through large variability in ensuing insurance losses. Other critical factors beyond precipitation are antecedent soil conditions, presence and condition of storm water infrastructure and snow melt.

The frequency-damage curve provides a plausible representation of the costs incurred by extreme precipitation events. Not every extreme event can be associated with high insurance losses; however this may be a function of the imperfect reporting and claims record rather than losses incurred. Many of the most extreme flooding events and therefore the most damaging conditions are directly attributable to very high levels of precipitation, even as observed at the national scale.

\subsection{Spatial Heterogeneity}

The analysis described above has all been performed on the national level. This is the only scale appropriate given both the observational dataset and the grid resolution of the climate models. Clearly national averages hide significant small-scale variations and local extreme events. To illustrate the sort of structure lost at this resolution, we performed an analysis of a shorter daily record over the UK derived from observations (Met. Office, 2009). Figure 4 shows the spatial pattern in annual rainfall percentages associated with a 1 in 3 level of occurrence on the national average. Further work is required to assess the impact of the natural variability correction discussed here downscaled to provide a local relevance.

\subsection{Anthropogenic Climate Change}

The work presented was focussed on uncovering the role that natural climate variability has on estimates of extreme events. Nonetheless, the influence of anthropogenic climate change cannot be ignored (Figure 3) and has been investigated using the same approach (Figure 2). Alternative and more rigorous approaches exist to quantify the human influence on extreme events. An ideal methodology has been developed to capture the influence both for meteorological (Pall et al., 2011) and hydrological events (Schaller et al., 2016). This retrospective attribution technique is highly developed and could be adapted to provide more rigorous equivalents of those used here. However, the present methodology could be deployed much more rapidly and so would be a more pragmatic choice. Further work would be required to assess its adequacy. 
4. Figures and Table

\section{Cumulative Annual Rainfall from Very Wet Days [w. NAO]}

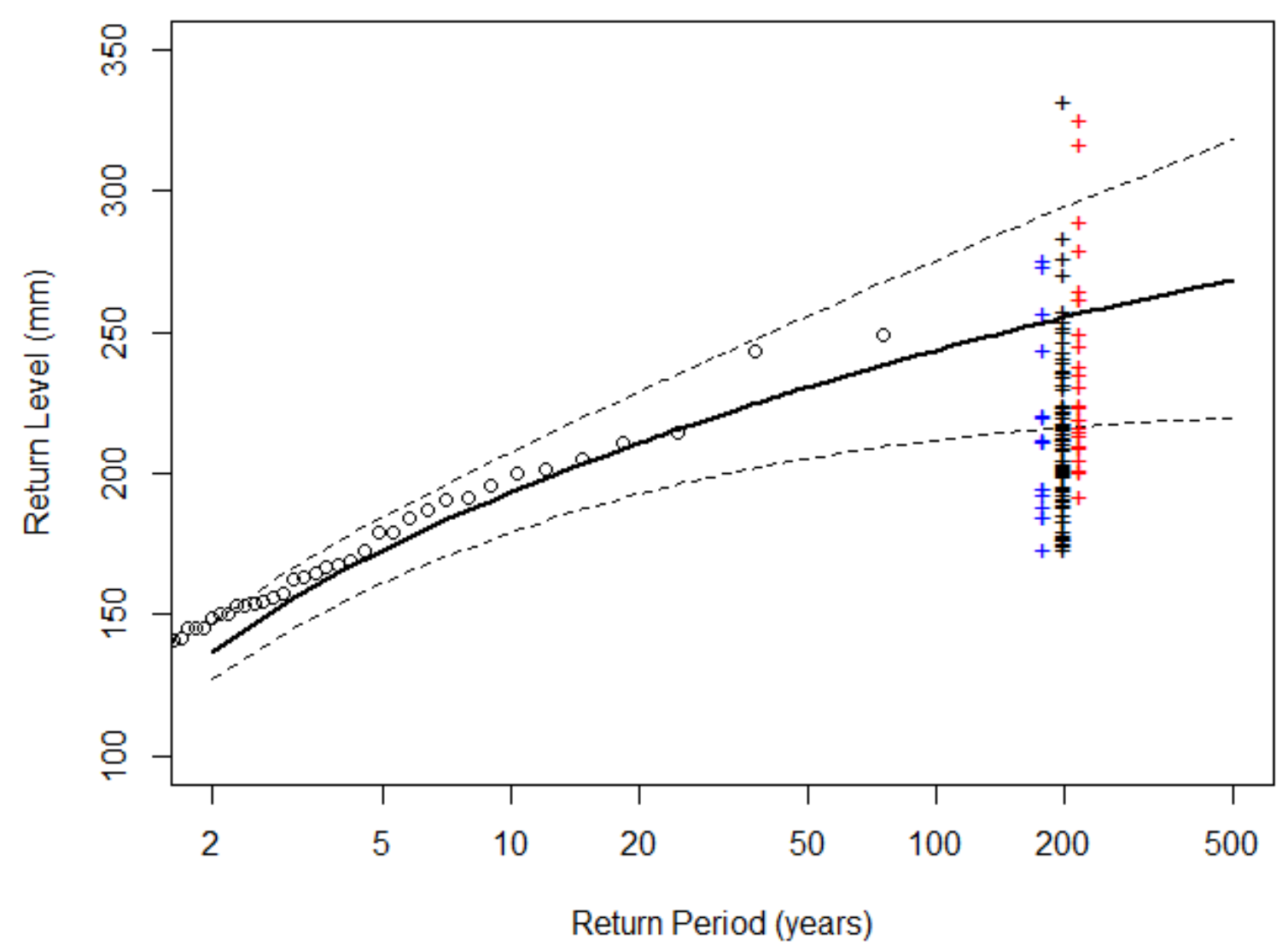

Figure 1. The return levels are estimated for cumulative annual rainfall from very wet days for England \& Wales. The estimated return levels are shown by black lines, along with its $5-95 \%$ confidence interval. The observed return levels seen in the rainfall data are shown by the circles. Simulated 200-yr return levels are shown with crosses - colour coded by the phase of the North Atlantic Oscillation (with blue for positive, black for neutral and red for negative). 


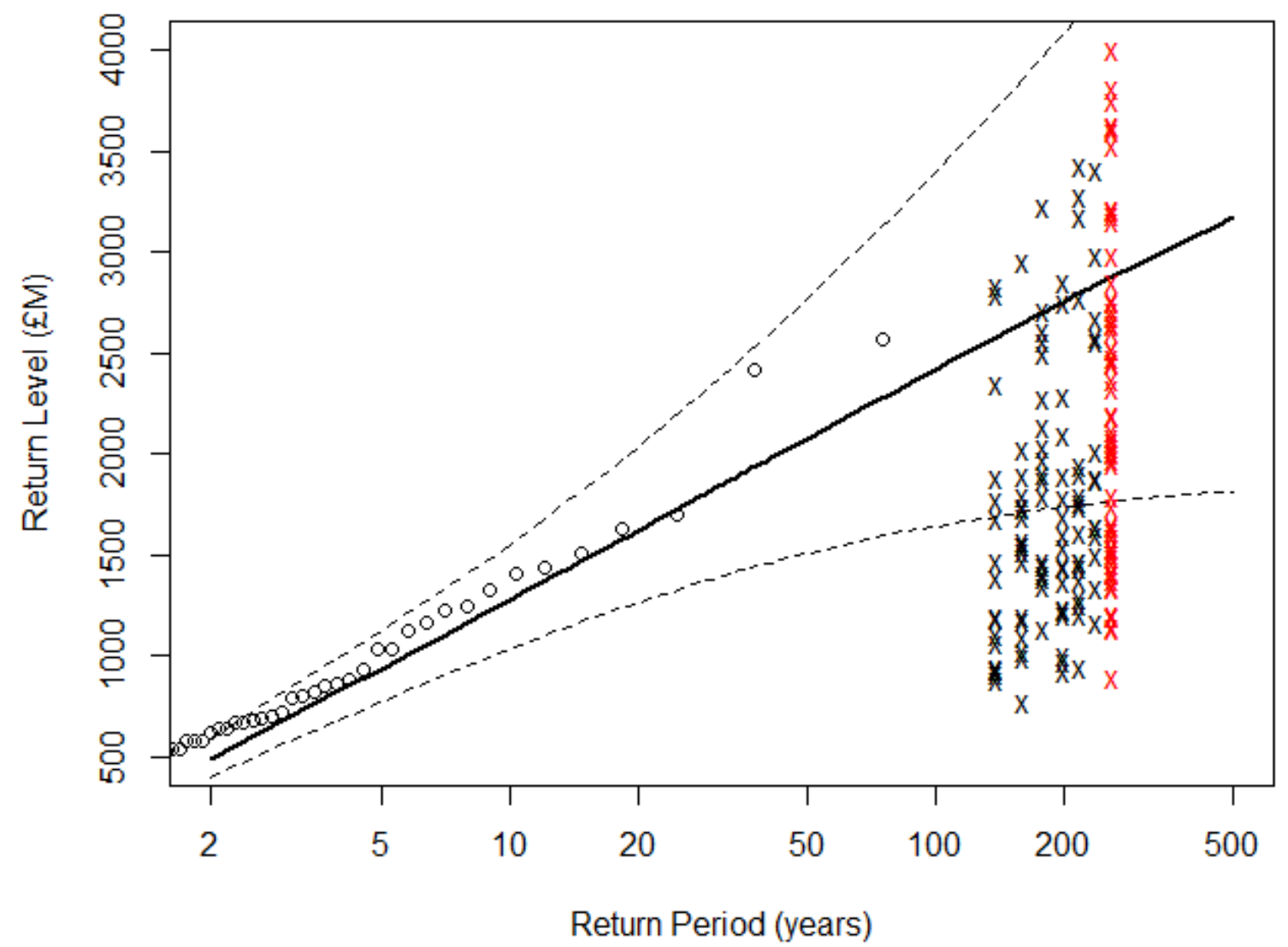

Figure 2. The return levels estimated for economic damage caused cumulative annual rainfall from very wet days for England \& Wales. The estimated return levels are shown by black lines, along with its $5-95 \%$ confidence interval. The observed return levels seen in the rainfall data are shown by the circles. Simulated 200-yr return levels calculated from twenty year records centred on 1895 (left) up to 2015 (right, red crosses).

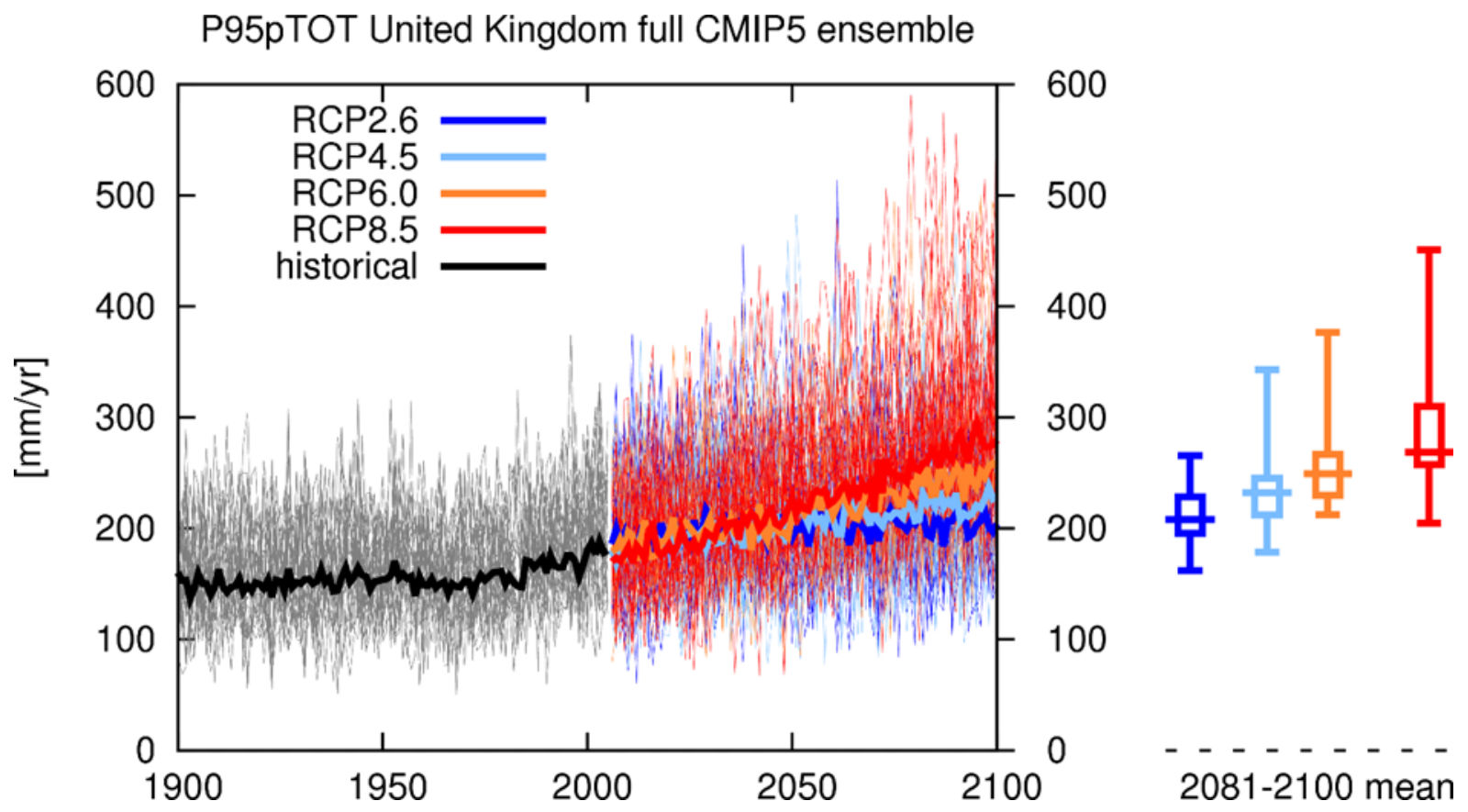

Figure 3. The cumulative annual rainfall from very wet days over the United Kingdom over the 20th and 21 st centuries, as simulated by climate models (generated using the IPCC's Climate Change Atlas; climexp.knmi.nl/plot_atlas_form.py). The ensemble mean and spread associated with various RCP scenarios (over the 2081-2100 period) are shown at the right. 


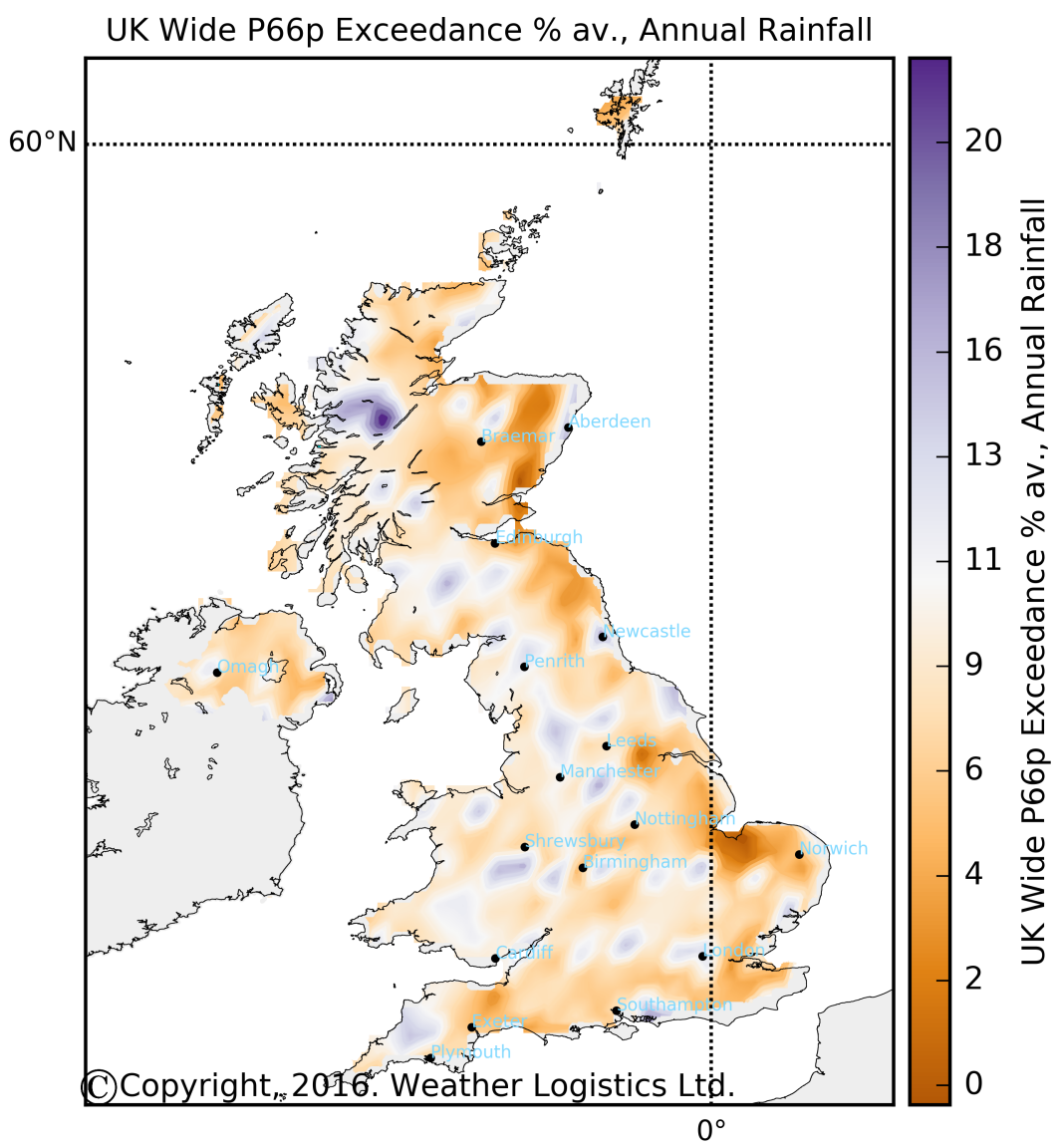

Figure 4. The local expression of rainfall extremes associated with a $66 \%$ (1 in 3 ) exceedance threshold in the national, annual mean value. Note that some locations see more extreme rainfall increases (blue), while some show much less (orange).

\begin{tabular}{|l|l|l|l|l|l|} 
Year & $\begin{array}{l}\text { R95pTOT } \\
(\mathrm{mm})\end{array}$ & $\begin{array}{l}\text { Cost } \\
(£ \mathrm{~m})\end{array}$ & $\begin{array}{l}\text { Cost } \\
(£ \mathrm{~m},\end{array}$ & $\begin{array}{l}\text { Reference } \\
\text { (Hyperlinked) }\end{array}$ & $\begin{array}{l}\text { Derived } \\
\text { Damage } \\
(£ m, 2015)\end{array}$ \\
\hline 2000 & 336.7 & 1000 & 1565 & Govt. Report & 5923 \\
\hline 2012 & 318.1 & 1190 & 1308 & Assoc. Brit. Insurers & 5061 \\
\hline 2002 & 298.2 & 2 & 3 & Glasgow Council & 4232 \\
\hline 2007 & 229 & 3200 & 4178 & House of Commons & 2038 \\
\hline 1965 & 226.3 & & & No cost found & 1972 \\
\hline 1981 & 225.3 & 1 & 3088 & York Council & 1948 \\
\hline 2008 & 223.4 & 35 & 44 & Env. Agency & 1903 \\
\hline 1998 & 222.8 & 350 & 575 & Met. Office & 1889 \\
\hline 1979 & 217.6 & & & No cost found & 1769 \\
\hline 1940 & 201 & & & No cost found & 1420 \\
\hline
\end{tabular}

Table.1. The reported losses resulting from the 10 years with the highest cumulative rain falling on very wet days. 


\section{References}

Ackerman, F. and Munitz, C., 2012. Climate damages in the FUND model: A disaggregated analysis. Ecological Economics, 77, pp.219-224.

Alexander, L.V. and Jones, P.D., 2000. Updated precipitation series for the UK and discussion of recent extremes. Atmospheric science letters, 1(2), pp.142-150.

Bronaugh, D., et al, 2015. PCIC Implementation of Climdex Routines. Available from: https://cran.r-project.org/web/packages/climdex.pcic/climdex.pcic.pdf

Dailey, P., Huddleston, M., Brown, S. and Fasking, D., 2009. The financial risks of climate change. Association of British Insurers Technical Report, AIR Worldwide Corp.

ETCCDI, 2009. Definitions of the 27 core indices. Available from: http://etccdi.pacificclimate.org/list_27_indices.shtml

Flato, G., Marotzke, J., Abiodun, B., Braconnot, P., Chou, S.C., Collins, W.J., Cox, P., Driouech, F., Emori, S., Eyring, V. and Forest, C., 2013. Evaluation of Climate Models. In: Climate Change 2013: Fifth Assessment Report of the Intergovernmental Panel on Climate Change. C. T. Stocker et al. (eds). Cambridge University Press, pp.741-866.

Green, C., 2003. Handbook of water economics: principles and practice. Wiley \& Sons.

Met. Office, 2009. UKCP09 Daily data sets. Available from www.metoffice.gov.uk/climatechange/science/monitoring/ukcp09/available/daily.html

Met. Office, 2016. HadUKP Data. Available from http://www.metoffice.gov.uk/hadobs/hadukp/data/download.html

Oppenheimer, M., Campos, M., Warren, R., Birkmann, J., Luber, G., O’Neill, B. C. and Takahashi, K. (2014). Emergent risks and key vulnerabilities. In Climate Change 2014: Fifth Assessment Report of the Intergovernmental Panel on Climate Change. C. B. Field et al. (eds). Cambridge University Press: pp.1039-1099.

Pall, P., Aina, T., Stone, D.A., Stott, P.A., Nozawa, T., Hilberts, A.G., Lohmann, D. and Allen, M.R., 2011. Anthropogenic greenhouse gas contribution to flood risk in England and Wales in autumn 2000. Nature, 470(7334), pp.382-385.

Penning-Rowsell, E., Floyd, P., Ramsbottom, D. and Surendran, S., 2005. Estimating injury and loss of life in floods: a deterministic framework. Natural Hazards, 36(1-2), pp.43-64.

Trenberth, K.E. and Shea, D.J., 2006. Atlantic hurricanes and natural variability in 2005. Geophysical Research Letters, 33(12).

Schaller, N., Kay, A.L., Lamb, R., Massey, N.R., Van Oldenborgh, G.J., Otto, F.E., Sparrow, S.N., Vautard, R., Yiou, P., Ashpole, I. and Bowery, A., 2016. Human influence on climate in the 2014 southern England winter floods and their impacts. Nature Climate Change, 6(6), pp.627-634.

Sillmann, J., Kharin, V.V., Zhang, X., Zwiers, F.W. and Bronaugh, D., 2013. Climate extremes indices in the CMIP5 multimodel ensemble: Part 1. Model evaluation in the present climate. Journal of Geophysical Research: Atmospheres, 118(4), pp.1716-1733. Data available from: http://www.cccma.ec.gc.ca/data/climdex/

Smith, D.I., 1994. Flood damage estimation- A review of urban stage-damage curves and loss functions. Water S. A., 20(3), pp.231-238.

Stephenson, D.B., Pavan, V., Collins, M., Junge, M.M. and Quadrelli, R., 2006. North Atlantic Oscillation response to transient greenhouse gas forcing and the impact on European winter climate: a CMIP2 multi-model assessment. Climate Dynamics, 27(4), pp.401-420.

van Oldenborgh, G.J., M. Collins, J. Arblaster, J.H. Christensen, J. Marotzke, S.B. Power, M. Rummukainen and T. Zhou. Annex I: Atlas of Global and Regional Climate Projections In: Climate Change 2013: Fifth Assessment Report of the Intergovernmental Panel on Climate Change. T. F. Stocker et al. (eds.)]. Cambridge University Press, pp. 1311-1394. Data available from: https://climexp.knmi.nl/plot_atlas_form.py 